Published in final edited form as:

Curr Opin Pediatr. 2016 October ; 28(5): 613-619. doi:10.1097/MOP.0000000000000398.

\title{
ABO-Incompatible Heart Transplantation
}

\author{
Simon Urschel, MD and Lori J. West, MD, DPhil \\ Department of Pediatrics, University of Alberta, Stollery Children's Hospital, Alberta Transplant \\ Institute
}

\begin{abstract}
Purpose-ABO-incompatible (ABOi) heart transplantation (HTx) in young children has evolved from an experimental approach to a standard allocation option in many countries. Clinical and immunological research in ABOi transplantation has revealed insight into the immature immune system and its role in superior graft acceptance in childhood and antigen-specific tolerance.
\end{abstract}

Recent Findings-Multicenter experience has confirmed equal actuarial survival, freedom from rejection and graft vasculopathy comparing $\mathrm{ABOi}$ to $\mathrm{ABO}-$ compatible (ABOc) HTx. Observations of reduced antibody production and B-cell immunity towards the donor blood group have been confirmed in long-term follow-up. Mechanisms contributing to tolerance in this setting involve the interplay between B-cells and the complement system and the development of B-cell memory. Better characterization of the $\mathrm{ABH}$ polysaccharide antigens has improved diagnostic methods and clinical assessment of blood group antibodies. Boundaries regarding age, immune maturity and therapeutic interventions to extend the applicability of ABOi HTx have been explored and resulted in data that may be useful for HTx patients beyond infancy and ABOi transplantation of other organs. Tolerance of ABH antigens possibly extends to HLA response.

Summary-This review provides insight into the clinical evolution of ABOi HTx and associated immunologic discoveries. Current experiences and boundaries are discussed together with recent and potential future developments for utilization in other patient and age groups.

\section{Keywords}

ABO-incompatible heart transplantation; immature immune system; polysaccharide immune response; T-independent B-cell activation; tolerance

\section{Introduction}

In 2001 West et al. reported the first series of 10 infants who received ABO-incompatible heart transplantation (ABOi HTx) in the Hospital for Sick Children in Toronto, Canada ${ }^{1}$. The attempt to cross a barrier previously considered insurmountable arose from a

Correspondence: Simon Urschel, MD, Associate Professor of Pediatrics and Immunology Director, Pediatric Cardiac Transplantation, 4C2.24, Walter McKenzie Center, 8440 - 112 Street, Edmonton, AB, T6G 2B7, Phone: +1 (780) 407 8361, Fax: +1 (780) 407 3310, urschel@ualberta.ca.

Conflicts of Interest:

The authors have no financial relationships influencing the content of the manuscript or leading to a conflict of interest.

Due to lack of licensure studies in the pediatric patient group, all medications mentioned in this review are 'off label', however, standard use for pediatric heart transplantation. 
combination of vigorous research on neonatal tolerance and a desperate clinical situation for neonates born with severe congenital heart disease facing greater than $50 \%$ mortality while waiting for an $\mathrm{ABO}-\mathrm{compatible}(\mathrm{ABOc})$ suitable donor. The following review will discuss the clinical development, underlying and resulting immunological aspects and current and possible future stage of this ABOi Tx.

\section{History and clinical evolution of ABO-incompatible heart transplantation}

Since Sir Peter Medawar's animal research in the 1950's ${ }^{2}$ growing evidence was found that the immature immune system of the neonate and infant may provide a unique window of opportunity for better acceptance of transplanted organs than any time later in life.

Concomitantly, unrelated research on the development of 'natural' $\mathrm{ABO}$ antibodies found that the response towards polysaccharides including the $\mathrm{ABH}$ blood group antigens was reduced or absent in the first six to 24 months of life ${ }^{3}$. In the same age range children show a high frequency and severity of infections with bacteria with polysaccharide encapsulation and lack of antibody production to pure polysaccharide vaccines against these pathogens, also a reflection of an inadequate immune response to carbohydrate structures ${ }^{4}$.

Accordingly, antibodies against the non-self blood group antigens, which are ubiquitous amongst adults and older children, were found to be absent in this age group, slowly evolving starting from the second half of the first year of life. Exposure to human tissue or blood is not required and the antibodies appear to develop in a mimicry reaction with response to intestinal bacteria. Exposure to $E$. coli accelerates and increases the formation of antibodies against blood group A, as shown in ethically questionable studies of the 1960 's ${ }^{5}$. The intent of the trial by West et al. was to use this window of immaturity of the immune system to transplant an ABOi organ safely and to control the development of immune response towards the donor blood group antigen(s) with standard immune suppression. Thus infants desperately awaiting transplant could have expanded access to organs independent of the donor blood group, resulting in greater numbers of children surviving to transplant and lower proportion of donor organs being wasted ${ }^{6}$. Exceeding these goals, the first ten patients showed a unique change in development of blood group directed antibodies in the years after transplant ${ }^{1,7}$ : antibodies towards the donor blood group as measured by dilution titers for agglutination of red blood cells remained absent or very low. In contrast, in blood group $\mathrm{O}$ patients antibodies towards the non-self, non-donor blood group developed normally, indicating that this was an antigen-specific effect rather than a globally reduced immune response. Encouraged by these findings and the compelling concept the approach was included as a general option in the Canadian listing guidelines and embraced by the pediatric transplant center for western Canada in Edmonton, Alberta; reduction of wait-list mortality due to optimized organ allocation was documented by both centers ${ }^{8}$. The first cases outside Canada were published from Munich, Germany ${ }^{9}$, followed by a successful series of 21 patients from the United Kingdom ${ }^{10}$. Eventually UNOS policies started to allow allocation of infant hearts to ABOi recipients in the U.S., however, only secondarily if the organ was not claimed first for an $\mathrm{ABO}$ identical then an $\mathrm{ABOc}$ recipient, and with very restrictive criteria for the recipient (isoagglutinin titers $<1: 4$ and age $<1$ year). Due to these restrictions but also given the natural scepticism towards potentially risky new approaches, the initial ABOi cohort transplanted in the Unites States showed a significantly worse risk profile than 
ABOc recipients ${ }^{11}$, but nevertheless showed equal survival and no increased frequency of acute rejection in the first year. Despite this cautious approach Everitt et al. reported shorter wait times to transplant for ABOi recipients in the US ${ }^{12}$. Long-term data from the original cohort in Toronto confirmed similar rates of acute rejection and graft vasculopathy when comparing infant recipients of $\mathrm{ABO}$ and $\mathrm{ABOc}$ transplants ${ }^{13}$. The cohort also continued to show antigen-specific tolerance to the donor blood group with isoagglutinin titers towards the donor blood group remaining absent or multiple log-steps below normal values and no reported cases of late antibody-mediated rejection (AMR) ${ }^{14}$. Data from the largest cohort to date were compiled in an international study on 55 patients from 7 centers in Canada, Europe and the United States ${ }^{15}$. This report showed excellent long-term survival, persistent absence of clinically relevant donor-directed isoagglutinin titers and freedom from ABOassociated AMR. Recent clinical effort focuses on exploring the limits and boundaries. In 2015 Irving et al. reported outcomes of patients whose ages and isoagglutinin titers would previously have been considered prohibitive, with reasonable success rates in patients up to 8 years of age and with titers as high as $1: 256^{16}$. Similarly, older patients receiving B-cell depletion for HLA sensitization may become candidates for ABOi transplant after experiencing reduction in isoagglutinins, reflecting depletion of their blood group directed B-cell immunity ${ }^{17}$. Tyden et al. reported successful intentional ABOi HTx in two carefully selected and pre-treated adults ${ }^{18}$. A recent analysis of the ISHLT registry database reported outcomes of all ABOi transplanted adult patients, mostly performed unintentionally thus not pre-treated and without use of appropriate group blood products to avoid passive antibody ${ }^{19}$. This study found a high mortality of $35 \%$ in the first year, however, similar conditional survival after the first year as for ABOc recipients.

Increasing numbers of reports are published on successful ABOi transplantation of various organs (kidney lung, liver) in children and adults. ABOi kidney Tx is a standard approach in Japan due to nearly non-existent deceased donation and has been found to provide good graft survival, however, using aggressive pre- and post-transplant antibody removal and immune suppressive strategies ${ }^{20}$. Given the 'safety-net' of dialysis rescue treatment for patients whose kidney grafts fail, transplant nephrologists are willing to take higher risks than in other organ groups. Pre-treatment in this setting has evolved from very aggressive pre-conditioning with splenectomy and cyclophosphamide to predominantly targeted B-cell depletion with rituximab together with antibody removal by immunoadsorption or plasmapheresis $^{21}$. The need for ongoing B-cell depletion and antibody removal in adult patients remains controversial since long-term persistent graft functionality has been observed despite the presence of donor-directed isoagglutinins and complement deposition in graft biopsies ${ }^{22}$, indicating 'accommodation' of the transplanted organ to some degree of antibody exposure.

\section{Immunology of ABO-incompatible transplantation}

The detection of specific tolerance to the donor blood group as reflected by absence of isoagglutinins was beyond the expectations of survival of ABOi heart grafts under moderate immune suppression, even as the recipient children were aging and their immune systems maturing. Blood group $\mathrm{O}$ recipients provide excellent insight into antibody development against the donor blood group, which remains absent or reduced, whereas antibodies to the 
non-self, non-donor blood group develop to normal or only mildly reduced titers ${ }^{14,15}$. In 2004 Fan et al. described this phenomenon in the original cohort and were unable to detect B-cells producing antibodies directed towards the donor blood group ${ }^{7}$. The reduced antibody titers specifically to the donor blood group sometimes persisted even after re-transplantation with a compatible O-organ several years later ${ }^{23}$. The key aspect of the immune response towards the $\mathrm{ABH}$ antigens that define the $\mathrm{ABO}$-blood group system is probably their polysaccharide nature. $\mathrm{ABH}$ antigens are similar to the molecules forming the capsule of certain bacteria such as Hemophilus influenzae type B (HiB), Streptococcus pneumoniae and meningococcus. Infections with these encapsulated bacteria are much more common and severe during the first two years of life $^{3}$, the same period revealing reduced levels of $\mathrm{ABO}$ antibodies ${ }^{24}$ and allowing long-term tolerance of $\mathrm{ABH}$ antigens after ABOi heart transplant. In contrast, immune response to peptide and protein antigens was found to be functional as early as the first days of life and yield specific antibody production against HLA after cardiac surgeries using vascular homografts 25 .

Accordingly, the mechanisms underlying blood group tolerance are likely to be found in the immune response towards polysaccharides. Absence of sufficient antibody production following vaccination with pure polysaccharide vaccines in the first two years of life was noticed in the 1980's. In contrast to peptides, polysaccharides are not presented by the major histocompatibility complex (MHC) class II. Consequently polysaccharides cannot induce the classical T-mediated B-cell response. This deficiency can be overcome by conjugation of the polysaccharide antigens to a protein component, a principle that has been successfully used in conjugate-vaccines for infants, first against $\mathrm{HiB}^{26}$, and more recently against pneumococcus ${ }^{27}$ and meningococcus ${ }^{28}$ strains. CD4 T-cells that have been activated against peptide parts of the conjugate presented via MHC II, activate not only B-cells that have bound the peptide parts but also those specific for the polysaccharide antigens of the conjugate vaccine via CD40-CD40 ligand (CD40L) signalling ${ }^{29}$. Sufficient antibody production can be induced in children as young as two months of age $\mathrm{e}^{26}$.

Alternative pathways that allow B-cells to be activated, differentiate into plasma cells and produce specific antibodies towards polysaccharides, have somewhat incorrectly been termed 'T-independent' (TI) B-cell activation. 'MHC-independent' might be a more appropriate term, given that these pathways in vivo likely require signals from T-cells and a respective inflammatory environment.

Type $1 \mathrm{TI}$ is the response observed towards long-chained, highly repetitive polysaccharide structures such as the lipopolysaccharide component of bacterial walls. Multiple B-cells bind to different areas of the antigen and cross-activate each other resulting in polyclonal proliferation and differentiation into antibody-producing plasma cells. Whether this results in formation of B-cell memory remains controversial. Type 2 TI can activate single B-cells without a CD40L signal. Instead, it involves the B-cell co-receptor, which is formed by CD21, CD19 and CD81, activation of which reduces the amount of antigen required to activate the $\mathrm{B}$-cell to by 100 to 1000 -fold ${ }^{30}$. The B-cell co-receptor is activated by CD21 binding to its ligand, the complement split product $\mathrm{C} 3 \mathrm{~d}^{31}$. If a polysaccharide antigen is covered by $\mathrm{C} 3 \mathrm{~d}$ it can activate the binding $\mathrm{B}$-cell without a direct $\mathrm{T}$-cell signal ${ }^{32}$. While this 
may occur in vitro in complete absence of T-cells, in vivo, at least indirect interplay with Tcells appears likely.

Our group has hypothesized that immaturity of the linkage between the innate (C3d) and adaptive immune system (CD21) required for the TI-2 immune response plays a key role in the lack of specific immunity to polysaccharide antigens including those defining the blood groups. We further postulate that this immaturity facilitates clinically successful ABOi HTx and persistent antigen-specific tolerance in young children.

In transplanted children and healthy controls we have found that CD21-expressing B-cells are overall less frequent in young children and increase with age ${ }^{33}$. In contrast, C3d levels in peripheral blood do not show age dependency, however, were significantly lower in children after $\mathrm{ABOi}$ compared to $\mathrm{ABOc}$ transplantation. $\mathrm{C} 3 \mathrm{~d}$ deposition in graft biopsies was not found, accordingly $\mathrm{C} 3 \mathrm{~d}$ is likely not reduced due to a consumption process, but actively downregulated in the context of tolerance of the donor blood group antigens. Downregulation of complement has previously been described in the setting of accommodation after ABOi kidney transplantation in adults ${ }^{34}$ and in xenotranplantation models ${ }^{35}$.

We further found that CD27+ memory B-cells are the main B-cell population responding to TI stimulation, and that the IgM-expressing subgroup of these cells is specifically activated by non-self blood group erythrocytes ${ }^{36}$. These cells are nearly absent at birth in peripheral blood and spleen of healthy and transplanted children, reaching near adult levels only by about five years of age. Children after ABOi HTx remain deficient in IgM-expressing CD27+ B-cells but show higher quantities of IgG-expressing 'switched' memory B-cells, indicating that tolerance of the donor $\mathrm{ABH}$ antigens is associated with a general modification in the allo-immune response. In keeping with this, we have observed that children after ABOi HTx showed significantly lower prevalence of class II HLA antibodies than ABOc HTx recipients in the same age group ${ }^{37}$. This suggests that tolerance to the donor $\mathrm{ABH}$ antigens may result in an overall more accepting immune response to other (graft) antigens and a potential clinical benefit. However, clinical data to date show similar outcomes for young patients after ABOi and ABOc-HTx ${ }^{13}$. Despite reduced presence of HLA antibodies graft survival after ABOi-Tx is not superior, however, there is also no increased frequency of infections with encapsulated bacteria, as one could suspect as a consequence of the above mentioned alterations of B-cell immunity.

Table 1 summarizes some of the recognized aspects of the immune system contributing to antigen-specific tolerance after ABOi HTx; further mechanisms currently under investigation include the inhibitory receptor CD22 on B-cells, the role of regulatory B-cells and the signalling cascade of the B-cell co-receptor complex.

\section{Current approach and future directions}

ABOi HTx has evolved to a widely accepted standard option for infants in many allocation areas, however, inclusion criteria, limitations, management and monitoring approaches remain variable. Given the rarity of the event it is unlikely that prospective comparative trials 
can be conducted. The pioneer groups in Canada, UK and Germany mostly based the management on the original protocols developed by West et al, however, modifications and experiences have broadened the understanding and identified various successfully pursued pathways. The original protocol used polyclonal induction therapy with anti-thymocyte globulin (ATG) in all patients. One could speculate that a key role for development of tolerance lies in B-cell exposure to the foreign blood group antigen in the context of an absent or drastically reduced T-cell response, which would be the exact setting of ATG induction. However, our multicenter study revealed that ABOi HTx was equally successful with transient T-cell blockade using IL-2 receptor antagonists (IL2RA, basiliximab) and in two cases even with induction limited to high dose steroids ${ }^{15}$. Maintenance immune suppression was not different from the centers' standard approaches, which typically included a calcineurin inhibitor (CNI, mostly tacrolimus) in combination with mycophenolate mofetil, supported by low dose steroids over the first 3-12 months. However, single cases remained stable under other drug combinations or even CNI monotherapy ${ }^{15}$. Similarly it has become increasingly evident that patients with titers up to 1:4 towards the donor blood group at the time of transplantation, and possibly higher, require no antibody removal.

In our own center we have modified the standard approach to use ATG in cases with titers above 1:16 or additional risk factors (such as HLA sensitization, renal failure), IL2RA for the remaining patients, with everyone receiving 5 doses of $2 \mathrm{mg} / \mathrm{kg}$ prednisone followed by a rapid wean to $0.1 \mathrm{mg} / \mathrm{kg}$ prednisone equivalent at day 21 post-transplant. Similarly antibody removal from the bypass circuit is performed only at titers of 1:8 or above, and a large lumen central line for post-transplant plasmapheresis is placed only for patients with titers of 1:16 or above.

A challenge to application of ABOi organ transplantation, as well as comparison of protocols and post-transplant clinical courses arises from well-described lack of standardization in techniques to quantify $\mathrm{ABO}$ antibodies and to characterize their fine specificities and isotypes. For example, a comparison study in Japan having identical plasma samples assessed by hemaggutination in various hematologic laboratories revealed a spread of reported IgM titers by 6 steps for anti-A and 5 steps for anti-B antibody. Antibodies purported to be $\operatorname{IgG}$ isotype, assessed after DTT treatment resulted in reports across the full spectrum of titers with no normal distribution ${ }^{38}$. Of major importance for organ transplantation, we recently found that $\mathrm{ABH}$ antigen carbohydrate subtype chains expressed on erythrocytes are not identical to subtype chains expressed on vascular endothelium (ie, of cardiac tissue) ${ }^{39}$. Consequently antibody levels detected by erythrocyte agglutination assays may not be reflective of antibodies actually posing a threat to the transplanted organ. Reliance on inaccurate agglutination assays may result in unnecessary exclusion of consideration of patients for ABOi transplantation or in performance of antibody removal procedures that may not be needed. A recently developed $\mathrm{ABH}$-glycan microarray assay that fully characterizes and quantifies serum $\mathrm{ABO}$ antibodies towards the $\mathrm{ABH}$ antigens actually expressed on the graft will generate more precise information for effective clinical management ${ }^{40}$. The $\mathrm{ABH}$-microarray and additional glycomics-based tools will also allow further investigation of the immunobiology of the ABO system and its impact in organ transplantation, including mechanisms of immunity, tolerance and accommodation ${ }^{41}$. 


\section{Conclusion}

In summary, ABOi HTx has evolved from a desperate attempt to increase survival in an otherwise mostly moribund population of newborn children to a standard approach that increases access to heart transplantation in the first 1-2 years of life with similar long-term outcomes to $\mathrm{ABOc}$ transplantation. It has become clear that for determining donor-recipient acceptability for heart transplantation in early life, the $\mathrm{ABO}$ blood groups are simply irrelevant. Given the positive impact of ABOi heart allocation on decreasing transplant wait times and waitlist mortality it becomes increasingly difficult to justify not embracing this approach due to concerns arising from outdated dogma based on ABO-immunobiology in adults or because established allocation algorithms are 'too complex' to modify ${ }^{42}$. Furthermore, although limitations in regards to suitable age and maturity of the immune system are not yet determined, there are no obvious reasons why ABO-incompatibility should be a barrier for other organ transplants in early childhood, as emerging reports in lung ${ }^{43}$, liver ${ }^{44}$ and kidney ${ }^{45}$ transplantation indicate. The immunological studies in this unique patient population open a window to explore the impact of immaturity on the immune response to polysaccharide and combined antigens that may have major impact on treatment and prophylaxis of infectious diseases and also autoimmune mechanisms.

\section{Acknowledgments}

Financial support:

This manuscript was not directly supported with any funding. The research by the West and Urschel partly discussed here was supported through research grants from the Canadian Institutes of Health Research, The Transplantation Society, the German Research Foundation (Deutsche Forschungsgemeinschaft, DFG), the Stollery Children's Hospital Foundation/Women and Children's Health Research Institute (WCHRI), Alberta and the Gordon English family.

Dr. West and Dr. Urschel are Canadian National Transplant Research Program (CNTRP) investigators.

\section{Abbreviations}

ABOi Blood group (ABO) incompatible

ABOc Blood group (ABO) compatible

ABH Polysaccharide antigens defining ABO-blood groups

ATG Anti-thymocyte globulin

CD40L CD40 ligand

CNI Calcineurin inhibitor

HLA Human leukocyte antigen

HTx Heart transplantation

MHC Major histocompatibility complex

TI T-independent B-cell activation 
UNOS United Network for Organ Sharing

\section{References}

1. West LJ, Pollock-Barziv SM, Dipchand AI, et al. ABO-incompatible heart transplantation in infants. New England Journal of Medicine. 2001; 344:793-800. [PubMed: 11248154] •• The manuscript presenting the rationale and outcomes of the first 10 patients receiving intentional ABOi transplantation in infancy.

2. Billingham RE, Brent L, Medawar PB. The antigenic stimulus in transplantation immunity. Nature. 1956; 178:514-519. [PubMed: 13358786]

3. Rijkers GT, Sanders EAM, Breukels MA, et al. Infant B-cell response to polysaccharide determinants. Vaccine. 1998; 16:1400.

4. Rijkers GT, Dollekamp EG, Zegers BJM. The Invitro B-Cell Response to Pneumococcal Polysaccharides in Adults and Neonates. Scandinavian Journal of Immunology. 1987; 25:447-452. [PubMed: 3495866]

5. Springer GF, Horton RE. Blood group isoantibody stimulation in man by feeding blood group-active bacteria. J Clin Invest. 1969; 48:1280-1291. [PubMed: 4893685]

6. Pollock-BarZiv SM, McCrindle BW, West LJ, et al. Competing outcomes after neonatal and infant wait-listing for heart transplantation. J Heart Lung Transplant. 2007; 26:980-985. [PubMed: 17919616]

7. Fan XH, Ang A, BarZiv SMP, et al. Donor-specific B-cell tolerance after ABO-incompatible infant heart transplantation. Nature Medicine. 2004; 10:1227-1233. - The study showing deficient antibody production toward the donor blood group and lack of donor blood group directed B-cells in the original cohort.

8. West LJ, Karamlou T, Dipchand AI, et al. Impact on outcomes after listing and transplantation, of a strategy to accept $\mathrm{ABO}$ blood group-incompatible donor hearts for neonates and infants. Journal of Thoracic and Cardiovascular Surgery. 2006; 131:455-461. [PubMed: 16434278]

9. Schmoeckel M, Dabritz SH, Kozlik-Feldmann R, et al. Successful ABO-incompatible heart transplantation in two infants. Transpl Int. 2005; 18:1210-1214. [PubMed: 16162109]

10. Roche SL, Burch M, O'Sullivan J, et al. Multicenter experience of ABO-incompatible pediatric cardiac transplantation. Am J Transplant. 2008; 8:208-215. [PubMed: 18021280]

11. Henderson HT, Canter CE, Mahle WT, et al. ABO-incompatible heart transplantation: analysis of the Pediatric Heart Transplant Study (PHTS) database. J Heart Lung Transplant. 2012; 31:173179. [PubMed: 22305379]

12. Everitt MD, Donaldson AE, Casper TC, et al. Effect of ABO-incompatible listing on infant heart transplant waitlist outcomes: analysis of the United Network for Organ Sharing (UNOS) database. J Heart Lung Transplant. 2009; 28:1254-1260. [PubMed: 19782582]

13. Dipchand AI, Pollock BarZiv SM, Manlhiot C, et al. Equivalent outcomes for pediatric heart transplantation recipients: ABO-blood group incompatible versus $\mathrm{ABO}$-compatible. Am $\mathrm{J}$ Transplant. 2011; 10:389-397. - The long-term outcomes and comparison of clinical outcomes of the Toronto $\mathrm{ABOi}$ to $\mathrm{ABOc}$ transplant cohorts showing equal freedom from rejection, graft vasculopathy and PTLD.

14. Conway J, Manlhiot C, Allain-Rooney T, et al. Development of donor-specific isohemagglutinins following pediatric ABO-incompatible heart transplantation. Am J Transplant. 2012; 12:888-895. [PubMed: 22233357]

15. Urschel S, Larsen IM, Kirk R, et al. ABO-incompatible heart transplantation in early childhood: An international multicenter study of clinical experiences and limits. J Heart Lung Transplant. 2013; 32:285-292. [PubMed: 23305695] • The largest data set thus far presenting clinical outcomes, management and antibody development in 55 ABOi patients from 7 international centers.

16. Irving CA, Gennery AR, Carter V, et al. ABO-incompatible cardiac transplantation in pediatric patients with high isohemagglutinin titers. J Heart Lung Transplant. 2015; 34:1095-1102. [PubMed: 26116516] 
17. Seitz S, Buchholz H, Rebeyka I, et al. Mechanical ventricular assist device as a bridge to recovery post-ABO-incompatible heart transplantation for failed Fontan circulation. Transpl Int. 2014; 27:e54-e57. [PubMed: 24628869]

18. Tyden G, Hagerman I, Grinnemo KH, et al. Intentional ABO-incompatible heart transplantation: a case report of 2 adult patients. J Heart Lung Transplant. 2012; 31:1307-1310. [PubMed: 23107062]

19. Bergenfeldt H, Andersson B, Bucin D, et al. Outcomes after ABO-incompatible heart transplantation in adults: A registry study. J Heart Lung Transplant. 2015; 34:892-898. [PubMed: 25754241] - A retrospective analysis of adult ABOi heart transplants reported to the ISHLTregistry, showing that following high early mortality, the patients experience conditional long-term survival after the first year similar to ABOc patients.

20. Takahashi K, Saito K. ABO-incompatible kidney transplantation. Transplant Rev (Orlando). 2013; 27:1-8. [PubMed: 22902167]

21. Koo TY, Yang J. Current progress in ABO-incompatible kidney transplantation. Kidney Res Clin Pract. 2015; 34:170-179. [PubMed: 26484043]

22. Haas M, Rahman MH, Racusen LC, et al. C4d and C3d staining in biopsies of ABO- and HLAincompatible renal allografts: correlation with histologic findings. Am J Transplant. 2006; 6:1829_ 1840. [PubMed: 16889542]

23. Kohler S, Engmann R, Birnbaum J, et al. ABO-compatible retransplantation after ABOincompatible infant heart transplantation: absence of donor specific isohemagglutinins. Am J Transplant. 2014; 14:2903-2905. [PubMed: 25293954]

24. Fong SW, Qaqundah BY, Taylor WF. Developmental patterns of ABO isoagglutinins in normal children correlated with the effects of age, sex, and maternal isoagglutinins. Transfusion. 1974; 14:551-559. [PubMed: 4432260]

25. Shaddy RE, Hunter DD, Osborn KA, et al. Prospective analysis of HLA immunogenicity of cryopreserved valved allografts used in pediatric heart surgery. Circulation. 1996; 94:1063-1067. [PubMed: 8790047]

26. Granoff DM, Holmes SJ, Belshe RB, et al. Effect of carrier protein priming on antibody responses to Haemophilus influenzae type b conjugate vaccines in infants. JAMA. 1994; 272:1116-1121. [PubMed: 7933324]

27. Toltzis P, Jacobs MR. The epidemiology of childhood pneumococcal disease in the United States in the era of conjugate vaccine use. Infect Dis Clin North Am. 2005; 19:629-645. [PubMed: 16102653]

28. McVernon J, Maclennan J, Buttery J, et al. Safety and immunogenicity of meningococcus serogroup $\mathrm{C}$ conjugate vaccine administered as a primary or booster vaccination to healthy fouryear-old children. Pediatr Infect Dis J. 2002; 21:747-753. [PubMed: 12192163]

29. Grewal IS, Flavell RA. The role of CD40 ligand in costimulation and T-cell activation. Immunol Rev. 1996; 153:85-106. [PubMed: 9010720]

30. Boackle SA, Holers VM, Karp DR. CD21 augments antigen presentation in immune individuals. European Journal of Immunology. 1997; 27:122-129. [PubMed: 9022008]

31. Rickert RC. Regulation of B lymphocyte activation by complement C3 and the B cell coreceptor complex. Current Opinion in Immunology. 2005; 17:237-243. [PubMed: 15886112]

32. Goud SN, Muthusamy N, Subbarao B. Differential responses of B cells from the spleen and lymph node to TNP-Ficoll. J Immunol. 1988; 140:2925-2930. [PubMed: 3129503]

33. Urschel S, Ryan LA, Larsen IM, et al. C3d plasma levels and CD21 expressing B-cells in children after ABO-incompatible heart transplantation: Alterations associated with blood group tolerance. J Heart Lung Transplant. 2014; 33:1149-1156. [PubMed: 24954883]

34. Platt JL, Cascalho M, West L. Lessons from cardiac transplantation in infancy. Pediatr Transplant. 2009; 13:814-819. [PubMed: 19254243]

35. Bach FH, Ferran C, Hechenleitner P, et al. Accommodation of vascularized xenografts: Expression of "protective genes" by donor endothelial cells in a host Th2 cytokine environment. Nature Medicine. 1997; 3:196-204.

36. Urschel S, Ryan LA, I ML, et al. Development of B-cell memory in early childhood and the impact on antigen-specific tolerance after heart transplantation. J Heart Lung Transplant. 2016; 35:491- 
499. [PubMed: 26856666] • Studies on the development of memory B-cells in heart transplanted children and healthy controls, providing insight into polysaccharide antigen-directed immune response in early childhood.

37. Urschel S, Campbell PM, Meyer SR, et al. Absence of donor-specific anti-HLA antibodies after ABO-incompatible heart transplantation in infancy: altered immunity or age? Am J Transplant. 2010; 10:149-156. [PubMed: 19951279] • A multicenter study showing lower prevalence of class II HLA antibodies in ABOi HTx childen indicating generally better graft acceptance.

38. Kobayashi T, Saito K. A series of surveys on assay for anti-A/B antibody by Japanese ABOincompatible Transplantation Committee. Xenotransplantation. 2006; 13:136-140. [PubMed: $16623808]$

39. Jeyakanthan M, Tao K, Zou L, et al. Chemical Basis for Qualitative and Quantitative Differences Between ABO Blood Groups and Subgroups: Implications for Organ Transplantation. Am J Transplant. 2015; 15:2602-2615. [PubMed: 26014598]

40. Jeyakanthan M, Meloncelli PJ, Zou L, et al. ABH-Glycan Microarray Characterizes ABO Subtype Antibodies: Fine Specificity of Immune Tolerance After ABO-Incompatible Transplantation. Am J Transplant. 2016; 16:1548-1558. [PubMed: 26602221]

41. Slaney AM, Dijke IE, Jeyakanthan M, et al. Conjugation of A and B Blood Group Structures to Silica Microparticles for the Detection of Antigen-Specific B Cells. Bioconjug Chem. 2016; 27:705-715. [PubMed: 26816334]

42. West LJ, Platt JL. And justice for all: consideration of ABO compatibility in allocation of hearts for infant transplantation. Circulation. 2010; 121:1884-1886. [PubMed: 20404260]

43. Grasemann H, de Perrot M, Bendiak GN, et al. ABO-incompatible lung transplantation in an infant. Am J Transplant. 2012; 12:779-781. [PubMed: 22152044]

44. Okada N, Sanada Y, Hirata Y, et al. The impact of rituximab in ABO-incompatible pediatric living donor liver transplantation: the experience of a single center. Pediatr Transplant. 2015; 19:279_ 286. [PubMed: 25689881]

45. Ohta T, Kawaguchi H, Hattori M, et al. ABO-incompatible pediatric kidney transplantation in a single-center trial. Pediatr Nephrol. 2000; 14:1-5. [PubMed: 10654320] 


\section{Key findings}

- $\quad$ ABOi HTx has evolved into a standard approach for young children with similar outcomes as $\mathrm{ABOc}$ transplant.

- $\quad$ ABOi HTx may be an option for older children and adults after careful selection and preparation and is likely a suitable option for other solid organ transplants.

- $\quad$ Tolerance to the ABH-antigens is associated with immaturity of the interplay of complement and its receptor on the B-cell (CD21)

- $\quad$ Lack of B-cell memory facilitates development of ABH tolerance and B-cell memory development is altered in presence of a tolerated ABOi heart.

- Tolerance of $\mathrm{ABH}$ antigens is associated with lower prevalence of class II HLA antibodies. 


\section{Table 1}

Mechanisms involved in blood group antigen-specific tolerance after ABOi transplant.

\begin{tabular}{|c|c|c|c|}
\hline Component & Function & Maturation & Role in ABOi transplant \\
\hline CD21 & $\begin{array}{l}\text { Receptor for complement split product } \\
\text { C3d, as part of the B-cell co-receptor } \\
\text { complex. Activation enhances CD40L } \\
\text { independent B-cell activation. Highly } \\
\text { expressed by marginal zone B-cells. }\end{array}$ & $\begin{array}{l}\text { Reduced frequency of CD } 21- \\
\text { expressing B-cells in the first } 6 \\
\text { months of age reflective of overall } \\
\text { lower B-cell frequency. } \\
\text { Different signalling pattern after } \\
\text { activation compared to adult cells. }\end{array}$ & $\begin{array}{l}\text { Similar presence in } \mathrm{ABOi} \text { and } \mathrm{ABOc} \\
\text { transplanted } \\
\text { children. }\end{array}$ \\
\hline C3d & $\begin{array}{l}\text { Complement split product. Part of first } \\
\text { line defense against polysaccharides and } \\
\text { ligand to CD21 on the B-cell. Ligation of } \\
\text { C3d to CD21 facilitates CD40L } \\
\text { independent B-cell activation ('TI type 2'). }\end{array}$ & $\begin{array}{l}\text { Peripheral plasma concentrations } \\
\text { appear not age-dependent. }\end{array}$ & $\begin{array}{l}\text { Significantly reduced in plasma of } \\
\text { recipients after } \\
\text { ABOi transplant, possibly secondary to } \\
\text { active } \\
\text { downregulation facilitating blood group } \\
\text { specific } \\
\text { tolerance. }\end{array}$ \\
\hline $\begin{array}{l}\text { CD27+ } \\
\text { memory B- } \\
\text { cells }\end{array}$ & $\begin{array}{l}\text { B-cells that can be quickly activated and } \\
\text { differentiate into plasma cells without } \\
\text { requiring T-cell-mediated activation } \\
\text { following exposure to their specific } \\
\text { antigen. Isotype-switched (IgG-expressing } \\
\text { / IgM negative) if previously activated } \\
\text { with a CD40L signal, otherwise IgM- } \\
\text { and/or IgD-expressing. Strongest } \\
\text { mediator of TI B-cell activation. Very } \\
\text { common in splenic marginal zone. }\end{array}$ & $\begin{array}{l}\text { Absent or very small numbers at } \\
\text { birth and gradually increasing to } \\
\text { adult proportions around } 5 \text { years of } \\
\text { age. Ongoing formation of new } \\
\text { specificities throughout adult life } \\
\text { with exposure to new antigens. }\end{array}$ & $\begin{array}{l}\text { IgM-expressing CD27+ B-cells show } \\
\text { specific activation } \\
\text { towards non-self blood group erythrocytes. } \\
\text { Low } \\
\text { proportions are associated with low } \\
\text { isoagglutinin } \\
\text { titers and likely provide the environment } \\
\text { for } \\
\text { successful ABOi transplant. } \\
\text { After ABOi transplant B-cell memory is } \\
\text { skewed } \\
\text { towards less IgM-expressing and more } \\
\text { 'switched' } \\
\text { CD27+ B-cells. }\end{array}$ \\
\hline
\end{tabular}

